\title{
DIREITO DE PRIVACIDADE NO DIREITO BRASILEIRO E NORTE AMERICANO
}

Luciana Vasco da Silva

ISSUE DOI: $10.21207 / 1983.4225 .262$

\section{RESUMO}

O presente artigo tem por finalidade comparar o direito à privacidade na sociedade moderna brasileira e americana. Comparar-se-ão decisões judiciais sobre o tema de privacidade e analisar-se-á a fundamentação ao Direito à intimidade e privacidade em ambos os ordenamentos jurídicos. O texto demonstrará a dimensão negativa do direito à privacidade, ou seja, aquela que protege a intimidade e a vida privada do indivíduo contra intromissões do poder público e dos demais cidadãos e a dimensão positiva, onde se impõe ao Estado o dever de implementar as medidas administrativas e legislativas para garantir a privacidade dos cidadãos, protegendo-os de ações de outros cidadãos e do próprio Estado, principalmente nos meios tecnológicos

Palavras-chave: Direito à privacidade. Direito da personalidade. Tecnologia da informação.

\section{INTRODUÇÃO}

Diante do progresso tecnológico, com a evolução dos meios de comunicação, verifica-se a vulnerabilidade da intimidade da pessoa humana. Torna-se relevante a discussão sobre os limites da vida privada e do interesse público. A referida discussão é problemática em todos os 
lugares, tendo cada sistema um posicionamento e um embasamento, porém todos com a finalidade de proteger a vida privada.

Nos Estados Unidos, o Direito a Privacidade é baseado no artigo Right To Privacy e a jurisprudência o utiliza até os dias atuais, limitando o interesse público à privacidade do indivíduo.

No Brasil, a principal controvérsia é a consideração do direito à privacidade como limitador do direito à personalidade. Discute-se, na doutrina interna, qual o limite do interesse público e o direito à privacidade, o mesmo direito de estar só previsto no ordenamento americano.

Com o advento da tecnologia a questão torna-se ainda mais relevante, pois o próprio agente expõe sua privacidade em mídias sociais.

A Jurisprudência ainda não é uniforme quanto à disponibilidade de informações privadas e qual o limite para tal ato. Há legislação versando sobre o assunto em vários campos, porém o mais importante é o recém editado Marco Civil da Internet, que estabelece os tipos de informações que serão consideradas privadas na rede e o tempo de guarda.

Verificar-se-á se há ou não pontos em comum entre o entendimento de privacidade no sistema jurídico Commom Law e o Direito Positivado brasileiro.

\section{SURGIMENTO DA PRIVACIDADE}

O conceito de privacidade nasceu na filosofia antiga, com as distinções quanto aos domínios do público e do privado. Na Grécia antiga, o interesse do Estado era superior ao interesse particular. Com o declínio da vida política grega, após a invasão macedônica, o interesse filosófico dirigiu-se da vida pública para a vida privada, valorizando assim a intimidade do cidadão.

Com o declínio da sociedade feudal, na qual o isolamento era privilégio de poucos, a privacidade passa a ser estendida a todos como elemento de promoção da igualdade de tratamento entre os cidadãos e da paridade social.

Na América e na Europa, até a primeira metade do século XIX, a defesa do direito à privacidade confundiu-se com a da propriedade privada e da honra, mas a partir da segunda metade do século XIX, a tutela da privacidade recebeu novos contornos. No século $\mathrm{XX}$, as inovações 
tecnológicas provocaram súbitas mudanças no conceito de privacidade, elevando o risco da violação. O desejo de obter informações sobre pessoas tornou-se crescente. ${ }^{1}$

Em 1948, surgiu a Declaração Americana dos Direitos e Deveres do Homem, proteção internacional do direito à privacidade, que no artigo $5^{\circ}$, dispõe o seguinte: "toda pessoa tem direito à proteção da lei contra os ataques abusivos a sua honra, a sua reputação e a sua vida privada e familiar". 2

No mesmo ano, foi aprovada pela Assembléia Geral das Nações Unidas em 10 de dezembro, a Declaração Universal de Direitos do Homem, que enunciava em seu art. 12 que "ninguém será objeto de ingerências arbitrárias em sua vida privada, sua família, seu domicílio ou sua correspondência, nem de ataques a sua honra ou a sua reputação. Toda pessoa tem direito à proteção da lei contra tais ingerências ou ataques".

\section{CONCEITO DE PRIVACIDADE E JULGAMENTOS NORTE-AMERICANOS}

A mais bem-sucedida definição da privacidade é de autoria do Juiz norte-americano Cooley. Em 1873, esse Juiz identificou a privacidade como: "The right to be let alone", ou como o direito de uma pessoa em ser deixada em paz, de estar só. ${ }^{3} \mathrm{~A}$ divulgação de informações exageradas, nos jornais de Boston resultou no artigo de Samuel Warren ${ }^{4}$ criticando a intervenção da mídia impressa. Esse right to be alone compreenderia a imunidade das pessoas em face da ação de repórteres, fotógrafos ou de pessoas que usem quaisquer aparelhos "modernos" de gravação ou reprodução de sons e imagens. Os autores do texto defendiam a não prevalên-

\footnotetext{
${ }^{1}$ NAVARRO, Ana Maria Neves de Paiva. Privacidade Informacional: origem e Fundamentos no Direito Norte-Americano. Publica Direito. Disponível em < http://www.publicadireito.com.br/artigos/?cod=34f9a343f945196b>. Acesso em 01.Dez.2014. p. 02.

2 SAMPAIO, J. A. L. Direito à intimidade e à vida privada. Belo Horizonte: Del Rey, 1998. p. 173.

${ }^{3}$ SILVEIRA, P. A. C. V. da. Proteção de dados no Direito Comparado. Revista AJURIS - n. 71 - Novembro/1997. p. 13.

4 SILVEIRA, P. A. C. V. da. Proteção de dados no Direito Comparado. Revista AJURIS - n. 71 - Novembro/1997. p. 13
} 
cia do interesse público, tendo em vista que determinados assuntos somente diriam respeito à vida privada.

Lawrence Lessing, estudioso contemporâneo do assunto, define como privacidade tudo o que "é o produto de uma relação entre tudo aquilo que pode ser monitorado ou investigado, e todas as proteções legais e estruturas utilizadas para dificultar este monitoramento e/ou investigação". 5

Atualmente, a Constituição Federal Americana não privilegia o Direito à Intimidade. Apenas algumas constituições estaduais como do Alaska (1972), Arizona (1912), Carolina do Sul (1970) resguardam o direito à intimidade e privacidade. Tendo em vista que o sistema judiciário americano é o da Commom Law, as decisões dos tribunais fazem lei entre as partes, sendo esse o norteador do Direito à intimidade.

Há várias manifestações jurisprudenciais sobre o limite de acesso à vida privada americana, dentre eles,o primeiro caso que é o emblemático Griswold v. Connecticut, 381 U. S. $479(1965)^{6}$, no qual indagavase até que ponto o governo podia intrometer-se na vida íntima de um casal a fim de decidir sobre métodos anticoncepcionais. Nesse caso, Estelle Griswold, diretora de uma liga de planejamento familiar e seu sócio Lee Buxton, médico e professor da Escola de Medicina da Universidade de Yale, montaram uma clínica de orientação de controle de natalidade em New Haven (Connecticut). Famoso ficou o voto do Justice William Douglas (1898-1980), quando ele falou que muitos dos direitos e garantias não previstos expressamente no Bill of Rights podiam ser extraídos hermeneuticamente das "penumbras" formadas por "emanações" que jorravam de outras proteções da própria Constituição. O Justice Hugo Black (1886-1971) discordou. Em interpretação nitidamente restritiva, ressaltou que o "direito à privacidade" (right to privacy) não se achava expresso em nenhum lugar da Constituição. O Justice Arthur Goldberg (19081990) contra-argumentou, dizendo que a Emenda n. 9 permitia a expansão de outros direitos que não aqueles assegurados expressamente no texto constitucional. Sendo assim, o Estado não poderia intervir na vida sexual, campo mais do que privado da intimidade.

\footnotetext{
${ }^{5}$ FINKELSTEIN, M. E. Direito do Comércio Eletrônico. 2. Ed. Rio de Janeiro: Elsevier, 2011. p. 109.

6 CF. Griswold v. Connecticut, 381 U.S. 479 (1965). Disponível em: <http://www.supreme.justia.com/cases/federal/us/.../case.html>. Acesso em: 25 de novembro 2014.
} 
Outro caso importante de Direito à privacidade é relatado entre Stanley v. Georgia, 394 U. S. $557^{7} \mathrm{em} \mathrm{1969.} \mathrm{Nesse} \mathrm{caso,} \mathrm{ampliou-se}$ ainda mais o "direito de intimidade". A polícia, munida de um mandado judicial, entrou na casa de Robert Stanley em busca de provas de que ele era "bicheiro". Nada relativo à atividade foi encontrado, porém, a polícia se deparou com três rolos de filmes pornográficos. Stanley foi condenado por possession of obscene materials. O Justice Thurgood Marshall (19081993), alude ao ideal americano da "busca pela felicidade" e invoca voto famoso de Louis Brandeis (1856-1941) em Olmstead v. United Sates, 277 U. S. 438, 478 (1928), quando o grande juiz sintetiza o "direito de privacidade" (right of privacy) como "o direito de ficar sozinho" (the right be let alone), "o mais compreensivo dos direitos e o direito mais valorizado pelos homens civilizados" (the most comprehensive of rights and the right most valued by civilized men). Ora, Stanley tinha o direito de ler ou ver na privacidade de seu lar aquilo que lhe comprazia. Não se negava ao Estado o poder de regulamentar a obscenidade. Mas, sem dúvida, esse poder não alcançava o indivíduo em seu próprio lar. Violado restou o direito de intimidade.

Atualmente, tema que tem frequentemente agitado os tribunais norte-americanos é o direito de a imprensa divulgar fatos da vida particular das pessoas. Muitas vezes fica difícil conciliar a liberdade de imprensa com o direito de privacidade do indivíduo. De um modo geral, a Suprema Corte tem entendido que, se o fato noticiado foi obtido de fonte pública e narrado com veracidade, está amparado constitucionalmente pela Emenda n. 1 (liberdade de imprensa). Existe um precedente que tem servido de norte para caso de divulgação de informação verídicas, de interesse público: Cox Broadcasting Corp. v. Cohn, 420 U. S. 469 (1975). ${ }^{8}$ Em 1971, em uma cidade da Geórgia, uma moça de 17 anos foi estuprada e assassinada. A lei estadual impedia a divulgação de foto e nome da vítima de estupro pela mídia. Um repórter da WSB-TV obteve cópia do processo com um funcionário do juízo e divulgou dados. O pai da vítima, com base na lei estadual, ajuizou ação exigindo punição e indenização. A Suprema Corte, por maioria esmagadora (vencido ficou o Justice Renhquist), teve a lei do Estado da Geórgia como inconstitucional. $\mathrm{O}$ direito à liberdade de

\footnotetext{
7 <http://www.supreme.justia.com/cases/federal/us/.../case.html>. Acesso em: 25 de novembro 2014.

8 <http://www.supreme.justia.com/cases/federal/us/.../case.html>. Acesso em: 25 de novembro 2014.
} 
imprensa prevalecia em relação ao direito de privacidade da vítima. Em seu voto, o Justice Byron White (1917-2002), que falou pela Corte, ressaltou: "O noticiário pela mídia é uma fonte importante para que os cidadãos possam fiscalizar a atividade governamental". Por outro lado, no caso concreto, as informações já se achavam publicamente registradas.

Os limites do direito à privacidade são constantemente postos à prova. Recentemente, no julgamento de United States $v$ Antoine Jones (julgado em 23 de janeiro de 2012) ${ }^{9}$, deliberou a Suprema Corte, por unanimidade, que é inconstitucional a instalação de rastreadores por Global Positioning System (GPS) em veículo, sem consentimento do proprietário ou autorização judicial, para efeito de monitoramento dos deslocamentos do motorista pela polícia.

Externando ainda mais o direito à privacidade, Lessig oferece o seguinte exemplo: supondo ser criado um programa que detecte arquivos ilegais no computador do cidadão, sem que o usuário investigado perceba a investigação. Que este programa não possa detectar nada além desse arquivo ilegal e que, se encontrado o determinado arquivo, esse o destrua ou, caso contrário, o programa se autodestrua. Nesse caso, haveria invasão de privacidade? Lessig entende que certamente há um senso de invasão, mas que a $4^{\text {a }}$ Emenda a Constituição norte-americana "já não está atrelada à invasão de privacidade, mas sim, à razoabilidade da invasão da privacidade." 10

\section{PRIVACIDADE NO MEIO ELETRÔNICO AMERICANO}

O problema entre o direito à privacidade e novas tecnologias não é exclusivo da contemporaneidade. Quando Warren e Brandeis (1890) escreveram seu artigo The Right to Privacy, a preocupação deles era com as novas tecnologias da época, como máquinas de fotografar e grandes jornais. ${ }^{11}$

\footnotetext{
9 Disponível em:< http://www.law.cornell.edu/supct/html/01-332.ZS.html>. Acesso em: 26 de nov 2014

${ }^{10}$ FINKELSTEIN, M. E. Direito do Comércio Eletrônico. 2. Ed. Rio de Janeiro: Elsevier, 2011. p. 109.

${ }^{11}$ BRANDÃO, A. M. Interpretação jurídica e Direito à Privacidade na Era da Informação: Uma abordagem hermenêutica filosófica. Revista Paradigma, Ribeirão Preto, A. XVIII, n. 22. p. 235.
} 
Em 1974, foi publicado o Federal Privacy Act ${ }^{12}$., uma legislação federal que passou a reger, no restrito âmbito das agências governamentais federais, as atividades de gerenciamento dos dados pessoais armazenados, permitindo a divulgação das informações individuais em restritas hipóteses e ampliando o acesso do interessado a seus dados pessoais (direito de acesso) $)^{13}$, inclusive para fins de solicitar a alteração deles (direito de retificação $)^{14}$. As agências são obrigadas a seguir, entre outros, os princípios de coletar apenas informações essenciais a suas atividades, coletá-las preferencialmente junto à própria pessoa, informar sobre os meios adotados para a coleta, publicar notícia acerca da natureza e da estrutura do banco de dados no Federal Register e não manter informações sobre como a pessoa exerce seus direitos individuais. ${ }^{15}$

No direito norte-americano, o problema de violação potencial dos dispositivos da lei de proteção da privacidade nos meios de comunicação eletrônica, a Electronic Communications Privacy Act de 1986 ("ECPA"), tem sido objeto de intenso debate. No caso do Google, a tecnologia AdSense associada às mensagens de correio eletrônico do GMail, não seria compatível com as normas da lei relacionadas aos crimes de interceptação eletrônica e de acesso não autorizado aos conteúdos armazenados na internet. A jurisprudência, no entanto, parece ter pouco aprofundado o tema, sustentando a não aplicação das normas da ECPA aos serviços de armazenamento de dados em comunicação eletrônica. Assim, se levado o argumento ao extremo, as mensagens recebidas e enviadas e, temporariamente armazenadas nos servidores do GMAIL, estariam excluídas do âmbito de proteção da lei, sobretudo pela privacidade de usuários situados em diferentes estados federados norte-americanos.

Em março de 2004, o Google deu início aos testes de seu serviço de correio eletrônico, o "G-Mail", tornando-se o centro das controvérsias no debate sobre privacidade e proteção de informações pessoais de usuários de internet. Isso teria contribuído para as primeiras linhas de leis

${ }^{12}$ ESTADOS UNIDOS. Departamento de Justiça dos Estados Unidos. Disponível em: <http://www.justice.gov/opcl/privstat.html>. Acesso em: 26. Nov. 2014

${ }^{13}$ Ibidem.

${ }^{14}$ Ibidem.

15 LINS, B.F.E. Privacidade e Internet. Estudo Legislativo. Disponível em: < http://www2.camara.leg.br/documentos-epesquisa/publicacoes/estnottec/tema4/pdf/001854.pdf>. Acesso em 27.nov. 2014. p.03. 
estaduais nos Estados Unidos sobre "privacidade online", a California online Privacy Protection Act de 2003.

Hoje os Estados Unidos têm leis estaduais como a Lei de Esquecimento, em que a postagem deve ser retirada do ar caso requerida, mas não são todos os Estados que aderiram à lei.

Por sua vez, a Câmara do Congresso norte-americano aprovou no mês de abril de 2014, o projeto de lei para compartilhamento de informações, o controverso Cyber e Protection Act (Cispa) ou HS-35. O Cispa permitirá, se houver a aprovação do presidente Barack Obama, às empresas entregarem dados confidenciais para o governo sem um mandado, sem anonimato, sem revisão judicial. Vale salientar que essa lei não vincula apenas cidadãos americanos e sim de todos os países, pois todos os usuários de computadores que tenham alguma relação com empresas norte-americanas, usando seus serviços, gratuitos ou pagos, poderão ter seus dados privados coletados, submetendo-se à vigência do Cispa.

Assim, o Cispa contraria o Marco Civil da Internet brasileiro, que por sua vez, pretende respeitar a privacidade do usuário na internet.

\section{PRIVACIDADE NA LEGISLAÇÃO BRASILEIRA}

A Constituição Federal brasileira dispõe no art. $5^{\circ}$ :

X - são invioláveis a intimidade, a vida privada, a honra e a imagem das pessoas, assegurado o direito a indenização pelo dano material ou moral decorrente de sua violação.

Segundo Celso Ribeiro Bastos, o direito à privacidade consiste na faculdade que tem cada indivíduo de obstar a intromissão de estranhos na sua vida privada e familiar, assim como de impedir-lhes acesso a informações sobre a privacidade de cada um e também impedir que sejam divulgadas informações sobre esta área da manifestação existencial do ser humano. ${ }^{16}$

\footnotetext{
${ }^{16}$ BASTOS, Celso Ribeiro. Curso de Direito Constitucional, 17 ed. São Paulo: Saraiva, 1989. p. 125
} 
Até mesmo para empresas existe o fenômeno da privacidade, há, inclusive, normas legais que proíbem a divulgação de dados de natureza confidencial da empresa, excetuados os casos das companhias abertas que, por exigência do mercado, são obrigadas a divulgar informações pertinentes, em certos casos.

O Direito à Privacidade é tão importante que possui menção em determinados regulamentos. O mais importante é a figura do habeas data, remédio para proteção da esfera íntima dos indivíduos e, contra usos abusivos de registros de dados pessoais coletados por meios ilícitos e meios de evitar a introdução de dados sensíveis nesses arquivos. Visa também desfazer a conservação de dados falsos ou com fins diversos dos previstos em lei.

No plano infraconstitucional, os dados pessoais são tutelados em legislações esparsas, dentre elas: o sigilo dos agentes do fisco (art. 198 do CTN), além das Leis n. ${ }^{\circ} 9.296 / 1996$ e n. ${ }^{\circ} 10.217 / 2001$, que tratam da interceptação telefônica e da gravação ambiental. Há, ainda, o Código de Defesa do Consumidor (Lei n. ${ }^{\circ}$ 8.078/1990), que trata dos bancos de dados nas relações de consumo, bem como a LC 105/2001, que permite às autoridades administrativas a quebra do sigilo bancário, em certas situações, sem autorização judicial. ${ }^{17}$

O Direito à Privacidade também está regulado no Novo Código Civil brasileiro, no Capítulo dos Direitos da Personalidade, em seu artigo 21, estabelece que "a vida privada da pessoa natural é inviolável, e o juiz, a requerimento do interessado, adotará as providências necessárias para impedir ou fazer cessar ato contrário a esta norma". No entanto, é importante destacar que, quando o interesse público predominar sobre o particular, a inviolabilidade da privacidade também reclama certas restrições, obrigando a análise caso a caso. Em algumas situações, encontramos exceções à proteção legal como em pessoas dotadas de notoriedade. ${ }^{18}$

Vale salientar que o direito à privacidade não deve ser definido sob a ótica do segredo. Atualmente, são quase inexistentes as informações que permanecem em absoluto sigilo. Na verdade, imaginar que o fato de

\footnotetext{
${ }^{17}$ LIMBERGER, T. O direito à intimidade na era da informática: a necessidade de proteção de dados pessoais. 2007. p. 147.

18 BLUM, R.M.S.O. Privacidade e os Tribunais. Revista Tema. Disponível em: <http://www1.serpro.gov.br/publicacoes/tema/166/materia15.htm> Acesso em 30.nov.2014. p. 01.
} 
uma informação não se mostrar como segredo não retira dela a proteção à privacidade.

Há uma tendência em entender que os fatos sigilosos, e somente eles, são protegidos pelo direito à privacidade. Isso significa que atitudes e acontecimentos tomados em âmbito público, ou até mesmo comunal, teriam caráter público, suficientes à exposição. Por exemplo, em uma festa em que participam 50 pessoas, um grupo de jovens embriaga-se e começa a praticar atos reprováveis socialmente. Se alguma dessas pessoas filmarem o incidente e divulgarem-no pela internet, poderemos considerar uma afronta à privacidade? Devemos, primeiramente, ponderar que a memória dos acontecimentos, na mente dos presentes, irá pouco a pouco se esvair, bem como suas conseqüências serão infinitamente menores do que um vídeo permanentemente disponível a qualquer um que queria assistir a ele. Não nos resta dúvida, portanto, que a caracterização de um fato como privado ou público não depende do ambiente em que o mesmo é praticado. ${ }^{19}$

Então quais serão os parâmetros para considerar um acontecimento sobre a tutela da privacidade? Solove afirma que a questão deve-se resolver pelo grau de acessibilidade. Com efeito, ao publicar um vídeo na internet, estaremos dando a esse fato um grau de acesso e conhecimento muito maior do que ele teria. Isso, por si só, já deve configurar uma afronta ao direito à privacidade. ${ }^{20}$

Anote-se, ainda, que com o advento da internet e a expansão das técnicas eletrônicas de comunicação no Brasil, a proteção à privacidade assumiu maior relevo. Até o surgimento da internet, essa preocupação com os dados pessoais restringia-se a duas importantes áreas: (a) os antecedentes criminais e (b) os registros creditícios, financeiros e econômicos.

As questões mais polêmicas na Internet estão relacionadas à falta de precauções com cookies, base de dados, práticas de spamming e monitoramento de e-mails.

$$
\text { Segundo Pablo Stolze (2003, p. 106): }
$$

${ }^{19}$ VIDAL, G. R. O direito à privacidade, os bancos de dados e as novas tecnologias. Jus Navigandi, Teresina, ano 15, n. 2626, 9 set. 2010. Disponível em: <http://jus.uol.com.br/revista/texto/17367>. Acesso em: 25 nov. 2014. p. 02.

${ }^{20}$ SOLOVE, D. J. The digital person: technology and privacy in the information age. New York: New York University Press, 2004. p. 01. 
Com o avanço tecnológico, os atentados à intimidade e á vida privada, inclusive por meio da rede mundial de computadores (Internet), tornaramse muito comuns. Não raro determinadas empresas obtêm dados pessoais do usuário (profissão, renda mensal, hobbies), com o propósito de ofertar os seus produtos, veiculando a sua publicidade por meio dos indesejáveis spams, técnica, ofensiva à intimidade e à vida privada. ${ }^{21}$

A fim de driblar a falta de privacidade na rede, os usuários utilizam-se do anonimato. Essa opção pode interferir sobre direitos fundamentais previstos na Carta Maior, a qual garante a liberdade de opinião, mas veda o anonimato (Constituição Federal Art. 5\%, IV). Por outro lado, essa prática pode fomentar atos ilícitos como o terrorismo e danos à moral de outras pessoas.

\section{PRIVACIDADE NA INTERNET E A JURISPRUDÊNCIA BRASILEIRA}

A privacidade na Internet relaciona-se, de forma análoga à imprensa, ou seja, será violação à privacidade, a divulgação, de dados ou fatos que atentem contra a intimidade, a vida privada, a honra e a imagem de uma pessoa. ${ }^{22}$

Além disso, a Internet traz um agravante: a rede é mundial e o fato poderá ser divulgado em escala nunca antes alcançada. Nela, muitas vezes, as informações são obtidas por meios ilícitos como: a) a coleta de informações no computador do usuário, sem o consentimento do proprietário; b) coleta ou compra de informações sobre o usuário em outros computadores, tais como o servidor que o atende ou os computadores de empresas cujos serviços a pessoa tenha utilizado; c) cruzamento das in-

${ }^{21}$ STOLZE, Pablo. Novo Curso de Direito Civil. Saraiva, São Paulo. Ed. 2003. p. 106.

${ }^{22}$ LINS, B.F.E. Privacidade e Internet. Estudo Legislativo. Disponível em: < http://www2.camara.leg.br/documentos-epesquisa/publicacoes/estnottec/tema4/pdf/001854.pdf>. Acesso em 27.nov. 2014. p. 05. 
formações sobre a pessoa, obtidas em sites diversos, sem o seu consentimento explícito etc.

Nos casos acima mencionados, o STJ afasta a possibilidade de utilização da imagem ou dados obtidos por meios inadequados, sem a autorização do titular, como segue:

Com o desenvolvimento da tecnologia, passa a existir um novo conceito de privacidade, sendo o consentimento do interessado o ponto de referência de todo o sistema de tutela da privacidade, direito que toda pessoa tem de dispor com exclusividade sobre as próprias informações, nelas incluindo o direito à imagem. (REsp 1168547 / RJ RECURSO ESPECIAL 2007/0252908-3 Ministro LUIS FELIPE SALOMÃO (1140) T4 - QUARTA TURMA 11/05/2010 DJe 07/02/2011).

Outra limitação, que pode ser observada na jurisprudência do STJ diz respeito à própria exposição do indivíduo como limitador de sua privacidade. Quando o próprio indivíduo se expõe a determinada situação, não pode requerer proteção a sua privacidade posteriormente. ${ }^{23}$

$\begin{array}{lccc}\text { DIREITO } & \text { CIVIL. DIREITO } & \text { DE } & \text { IMAGEM. } \\ \text { TOPLESS } & \text { PRATICADO } & \text { EM } & \text { CENÁRIO }\end{array}$ PÚBLICO. Não se pode cometer o delírio de, em nome do direito de privacidade, estabelecer-se uma redoma protetora em torno de uma pessoa para torná-la imune de qualquer veiculação atinente a sua imagem. Se a demandante expõe sua imagem em cenário público, não é ilícita ou indevida sua reprodução pela imprensa, uma vez que a proteção à privacidade encontra limite na própria exposição realizada. Recurso especial não conhecido. (REsp 595600 / SC; RECURSO ESPECIAL; 2003/0177033-2; Ministro CESAR ASFOR ROCHA (1098); T4 - QUARTA TURMA; 18/03/2004).

${ }^{23}$ BRANDÃO, A. M. Interpretação jurídica e Direito à Privacidade na Era da Informação: Uma abordagem hermenêutica filosófica. Revista Paradigma, Ribeirão Preto, A. XVIII, n. 22, p. 232-257, jan./dez. 2013. p. 247. 
Pode-se observar também, na jurisprudência do STJ, que quando há referência a um indivíduo de forma acidental, como em caso de uso de sua imagem sem consentimento, em um contexto onde o objetivo não era a exploração de sua imagem, por exemplo, não havendo prejuízo ao indivíduo, não há o que se falar em violação da privacidade. ${ }^{24}$

CIVIL. USO INDEVIDO DA IMAGEM. INDENIZAÇÃO DE DANOS MORAIS. O uso não autorizado de uma foto que atinge a própria pessoa, quanto ao decoro, honra, privacidade, etc., e, dependendo das circunstâncias, mesmo sem esses efeitos negativos, pode caracterizar o direito à indenização pelo dano moral, independentemente da prova de prejuízo. Hipótese, todavia, em que o autor da ação foi retratado de forma acidental, num contexto em que o objetivo não foi a exploração de sua imagem. Recurso especial não conhecido. (REsp 85905 / RJ; RECURSO ESPECIAL 1996/00023883; Ministro ARI PARGENDLER (1104); T3 TERCEIRA TURMA; 19/11/1999).

Outro grave problema que devassa a intimidade e a privacidade é com relação aos dados enviados pelo usuário para cadastro, já que quanto maior a utilização da tecnologia, melhor é o compartilhamento desses dados, possibilitando a formação de grandes bancos de dados contendo praticamente todas as informações sobre a vida da pessoa. ${ }^{25}$ Essas informações são compartilhadas sem o conhecimento do "investigado", tornando-as públicas para uma grande quantidade de empresas, como, por exemplo, as de crédito e financiamento, e, até mesmo, para golpistas e estelionatários.

O Código de Defesa do Consumidor é claro ao determinar que qualquer cadastro, ficha ou registro em nome do consumidor deverá ser

\footnotetext{
${ }^{24}$ BRANDÃO, A. M. Interpretação jurídica e Direito à Privacidade na Era da Informação: Uma abordagem hermenêutica filosófica. Revista Paradigma, Ribeirão Preto, A. XVIII, n. 22, p. 232-257, jan./dez. 2013. p. 248.

${ }^{25}$ RABANEDA, F. A legislação e o Direito da Informática. Âmbito jurídico, $n^{\circ} 67$, Ano XII, Agosto 2009 <http://ambitojuridico.com.br/site/index.php/abrebanner. php?n_link=revista_artigos_leitura\&artigo_id $=7193 \&$ revista_caderno $=17>$. Acesso em 25.nov.2014. p. 05.
} 
previamente comunicado por escrito, quando não solicitado por ele (parágrafo segundo da lei 8.078/90).

Podemos concluir que, de certa forma, aquele que acessa a internet tem cada um de seus atos monitorados permanentemente. ${ }^{26}$

\section{PRIVACIDADE E O MARCO CIVIL DA INTERNET}

O marco civil da internet foi discutido durante anos. Sua função é a de servir como uma constituição da internet na garantia de direitos como: neutralidade da rede, liberdade de expressão e privacidade na internet.

Os artigos $10^{\circ}$ e $11^{\circ}$ do Marco Civil tratam de dois itens importantes relacionados à privacidade dos usuários. O primeiro diz, dentre outras coisas, que um provedor não pode violar o direito à intimidade e vida privada dos seus usuários — ou seja, não pode divulgar seus dados ou ainda monitorar os dados trafegados. E o segundo diz que o monitoramento e armazenamento desses dados podem ser feitos desde que o provedor receba ordem judicial com essa instrução. O tempo de armazenamento dos dados foi alterado: antes era de 2 anos e agora será de no máximo um ano.

Vale lembrar que os provedores só deverão guardar o chamado "registro de conexão", que segundo o projeto é o "conjunto de informações referentes à data e hora de início e término de uma conexão à Internet, sua duração e o endereço IP utilizado pelo terminal para o envio e recebimento de pacotes de dados". Ou seja: eles devem guardar qual foi o IP, duração e quando essa conexão ocorreu. O registro não deve conter os sites acessados ou aplicações usadas.

Os parágrafos do artigo $7^{\circ}$ também preveem que, caso algum serviço web precise coletar dados pessoais, ele deve dar informações claras e completas sobre essa coleta - bem como excluir todos os dados caso o usuário termine seu contrato com a empresa e ainda oferecer "ter-

\footnotetext{
${ }^{26}$ FINKELSTEIN, M. E. Direito do Comércio Eletrônico. 2. Ed. Rio de Janeiro: Elsevier, 2011. p. 110.
} 
mos claros" sobre as políticas de uso da sua rede. E isso já é feito pela grande maioria de serviços, nos seus termos de uso. ${ }^{27}$

Segundo a nova lei, informações pessoais e registros de acesso só poderão ser vendidos se o usuário autorizar expressamente a operação comercial. Atualmente, os dados são coletados e vendidos pelas empresas, que têm acesso a detalhes sobre as preferências e opções dos internautas. $^{28}$

O texto também determina que as empresas desenvolvam mecanismos para garantir o sigilo e a privacidade das informações, como por exemplo, que os e-mails só sejam lidos pelos emissores e pelos destinatários da mensagem. Caso as empresas descumpram essa regra, poderão ser penalizadas com advertência, multa, suspensão e até proibição definitiva de suas atividades. E ainda existe a possibilidade de penalidades administrativas, cíveis e criminais.

\section{CONCLUSÃO}

Após analisarmos os dois ordenamentos jurídicos, o americano e o brasileiro, completamente distintos, pode-se concluir que ambos apresentam proteção à privacidade de forma semelhante.

Apesar de o sistema americano não ser positivado e o brasileiro o ser e apresentar várias menções à importância do Direito à Privacidade, entende-se que ainda há muito a discutir sobre o assunto.

Ambos os ordenamentos preocupam-se em garantir a vida privada, porém, em tempos de internet e redes sociais, torna-se difícil estabelecer limites à privacidade.

Logicamente, não é necessário que a informação seja sigilosa para que seja protegida e também o fato de estar em um grupo, por vezes, não caracteriza o ambiente como público, concedendo o direito de publicar os fatos na internet.

\footnotetext{
${ }^{27}$ SILVA, R. Marco Civil da Internet: o que ele diz sobre privacidade, o conteúdo na web e a neutralidade na rede. Tecnoblog, 2013. Disponível em: <https://tecnoblog.net/107123/marco-civil-internet/>. Acesso em 28.nov. 2014

${ }^{28}$ CRAIDE, S; MELO, K. Marco Civil da Internet entra em vigor hoje. Agência Brasil. 2014. Disponível em: <http://agenciabrasil.ebc.com.br/geral/noticia/2014-06/marcocivil-da-internet-entra-em-vigor-hoje>. Acesso em 02.Dez.2014. p. 01.
} 
A jurisprudência ainda é ambígua, em ambos os ordenamentos. Há ocasiões em que tenta ser o mais restritiva possível, em outras, entende que a informação foi disposta pelo próprio agente e, consequentemente, não o protege quanto ao Direito de Privacidade.

No âmbito da Internet, as ideologias dos dois ordenamentos são bem distintas. No Brasil, com o Marco Civil da Internet protegem-se os dados dos internautas. Já no Direito Norte-Americano, a linha de pensamento é contrária à Brasileira.

Como vimos no presente trabalho, o CISPA pretende divulgar, sem autorização, todos os dados de internauta, não só americanos: basta que as informações tenham sido guardadas em datacenters americanos, ou que se tenha acessado página de tal nacionalidade. Ou seja, o CISPA é totalmente contrário ao Marco Civil da Internet.

Esse aparente confronto de legislação ainda não tem solução. Caberá aos tribunais julgarem futuras lides sobre o assunto e delimitarem o que poderá ser danoso ou não à privacidade e intimidade do cidadão.

Vale salientar que o Direito a Privacidade no Brasil tem proteção constitucional e infraconstitucionalmente é considerado Direito de Personalidade, ou seja, um Direito que faz parte do próprio ser humano.

Cada vez mais nos depararemos com situações nas quais se deve sobrepesar o estímulo ao compartilhamento de informações e acabar com o limite quase tênue, da vida privada, aquela que o cidadão não quer "postar" nas redes sociais, que não quer que ninguém saiba: a intimidade do seio familiar.

\section{REFERÊNCIAS BIBLIOGRÁFICAS}

BASTOS, Celso Ribeiro. Curso de Direito Constitucional, 17 ed. São Paulo: Saraiva, 1989

BLUM, R.M.S.O. Privacidade e os Tribunais. Revista Tema. Disponível em: <http://www1.serpro.gov.br/publicacoes/tema/166/materia15.htm> Acesso em 30.nov.2014.

BRANDÃO, A. M. Interpretação jurídica e Direito à Privacidade na Era da Informação: Uma abordagem hermenêutica filosófica. Revista Paradigma, Ribeirão Preto, A. XVIII, n. 22, p. 232-257, jan./dez. 2013 
CRAIDE, S; MELO, K. Marco Civil da Internet entra em vigor hoje. Agência Brasil. 2014. Disponível em: <http://agenciabrasil.ebc.com.br/geral/noticia/2014-06/marco-civilda-internet-entra-em-vigor-hoje>. Acesso em 02.Dez.2014.

ESTADOS UNIDOS. Departamento de Justiça dos Estados Unidos. Disponível em: <http://www.justice.gov/opcl/privstat.html>. Acesso em: 26. Nov. 2014.

ESTADOS UNIDOS. Supreme Court of the United States. Disponível em:< http://www.law.cornell.edu/supct/html/01-332.ZS.html $>$ Acesso em: 26 de nov 2014.

FINKELSTEIN, M. E. Direito do Comércio Eletrônico. 2. Ed. Rio de Janeiro: Elsevier, 2011.

GAGLIANO, P. S.; PAMPLONA FILHO, R. M. Novo Curso de direitocivil: abrangendo o código de 1916 e o novo Código Civil (2002). 4.Ed., ver. E atual. São Paulo: Saraiva, 2003-2008.

LIMBERGER, T. O direito à intimidade na era da informática: a necessidade de proteção de dados pessoais. Porto Alegre, Livraria do Advogado. 2007

LINS, B.F.E. Privacidade e Internet. Estudo Legislativo. Disponível em: $\quad<\quad h t t p: / / w w w 2 . c a m a r a . l e g . b r / d o c u m e n t o s-e-$ pesquisa/publicacoes/estnottec/tema4/pdf/001854.pdf $>$. Acesso em 27.nov. 2014.

NAVARRO, Ana Maria Neves de Paiva. Privacidade Informacional: origem e Fundamentos no Direito Norte-Americano. Publica Direito. Disponível em http://www.publicadireito.com.br/artigos/?cod=34f9a343f945196b >. Acesso em 01.Dez.2014.

RABANEDA, F. A legislação e o Direito da Informática. Ambito Jurídico, $\mathrm{n}^{\mathrm{o}}$ 67, Ano XII, Agosto $2009<\mathrm{http} / /$ /ambitojuridico.com.br/site/index.php/abrebanner.php?n_link=revista_arti gos_leitura\&artigo_id=7193\&revista_caderno=17>. Acesso em 25.nov. 2014

SAMPAIO, J. A. L. Direito à intimidade e à vida privada. Belo Horzonte: Del Rey, 1998.

SILVA, R. Marco Civil da Internet: o que ele diz sobre privacidade, o conteúdo na web e a neutralidade na rede. Tecnoblog, 2013. Disponível em: <https://tecnoblog.net/107123/marco-civilinternet/>. Acesso em 28.nov. 2014 
SILVEIRA, P. A. C. V. da. Proteção de dados no Direito Comparado. Revista AJURIS - n. 71 - Novembro/1997

Site Pesquisado

Disponível em: <http://www.supreme.justia.com/cases/federal/us/.../case.html>. Acesso em: 25 de novembro 2014.

SOLOVE, D. J. The digital person: technology and privacy in the information age. New York: New York University Press, 2004.

StOLZE, Pablo. Novo Curso de Direito Civil. Saraiva, São Paulo. Ed. 2003. p. 106.

VIDAL, G. R. O direito à privacidade, os bancos de dados e as novas tecnologias. Jus Navigandi, Teresina, ano 15, n. 2626, 9 set. 2010. Disponível em: <http://jus.uol.com.br/revista/texto/17367>. Acesso em: 25 nov. 2014. 